Ensino, Saúde e Ambiente - V9 (3), pp. 283-296, Dez. 2016

\title{
USANDO O TEMA RISCOS QUÍMICOS EM ESPAÇOS NÃO FORMAIS DE ENSINO
}

\section{USING CHEMICAL HAZARDS IN NON-FORMAL EDUCATIONAL SPACES}

\author{
Romulo de Oliveira Pires ${ }^{1}$, Eline Deccache-Maia ${ }^{2}$, Jorge Cardoso Messeder ${ }^{3}$ \\ ${ }^{1}$ IFRJ-Campus Nilópolis, Licenciatura em Química, romulo_88@yahoo.com.br \\ 2 IFRJ-Campus Nilópolis, Mestrado em Ensino de Ciências, eline.maia@ifrj.edu.br \\ ${ }^{3}$ IFRJ- Campus Nilópolis, Mestrado em Ensino de Ciências, jorge.messeder@ifrj.edu.br
}

\section{RESUMO}

O conteúdo apresentado neste artigo é oriundo de um Trabalho de conclusão do Curso de Licenciatura em Química, cujo objetivo foi discutir o tema riscos químicos em ambientes domésticos através da análise da prática de ensino realizada em espaços fora da sala de aula. Na busca de assuntos significativos para a população do entorno do Instituto, foram realizadas palestras em ambientes não formais de ensino tendo como foco riscos químicos, visando reconhecer as lacunas destes saberes, utilizando questionário e conversas realizadas durante as visitas. Uma das metas do trabalho foi oferecer ao público participante conteúdos necessários para evitar acidentes e de primeiros socorros, tendo como suporte recursos de mídia. Os resultados encontrados demonstraram que existe um grande distanciamento entre os atuais objetivos do Ensino de Química e a conscientização sobre os riscos para saúde causados por situações do cotidiano da população, como é o caso do manuseio dos produtos domissanitários.

Palavras-chave: Riscos químicos. Espaços não formais. Prática de ensino

\begin{abstract}
The content presented in this article comes from a working conclusion of the Degree in Chemistry, whose aim was to discuss the subject chemical hazards in homes through the analysis of teaching practice performed in spaces outside the classroom. In search of significant issues for the surrounding population of the Institute, lectures were held in non-formal learning environments focusing on chemical risks, aiming to recognize the real needs of this knowledge, using a questionnaire and discussions held during the visits. One of the goals of the work was to provide the participating public the necessary knowledge to prevent accidents and first aid, supported media resources. The results showed that there is a large gap between the current objectives of Chemistry Teaching and awareness of the health risks caused by the population everyday situations such as the handling of household cleaning products.
\end{abstract}

Key words: Chemical Hazards. Spaces of Non-Formal Education. Teaching practice.

\section{INTRODUÇÃO}

A elaboração do planejamento anual da disciplina Química na Educação Básica tornou-se uma tarefa árdua para o professor ao deparar-se com o conservadorismo de correntes pedagógicas e do currículo mínimo que, por diversas vezes, não apresentam 
conformidade com a vida como ela de fato é, fazendo com que muitas vezes os alunos não se reconheçam nos assuntos trazidos em aula. A efetiva escolha dos temas a serem discutidos pelo professor tem como desafio inicial sua abordagem associada com os conteúdos, entrelaçando os mesmos com os existentes nos demais espaços sociais. Por que não considerar a possibilidade de incorporar assuntos relevantes para a comunidade escolar, para o universo familiar ou, até mesmo, os relacionados às manifestações religiosas? Tarefas como aprender a língua materna, normas de conduta, lavar roupa, realizar pequenos consertos, dançar, ou seja, aspectos que fazem parte da vida em sociedade (GASPAR, 2002), são habilidades que, por diversas vezes, permeiam variados espaços sociais, todos eles aspectos da realidade social aprendidos em espaços informais, sendo estes os primeiros conteúdos que o indivíduo terá contato e que carregará para dentro da escola. Na concepção de Gaspar:

\footnotetext{
...ambas, educação formal e informal, reforçam-se mutuamente. A mente humana não tem compartimentos estanques, guichês cognitivos que filtram ou validam conhecimentos em função da sua origem ou da forma pela qual eles são apresentados. Todo desafio e todo estímulo ao pensamento e à percepção enriquecem nossas estruturas cognitivas. (Gaspar, 2002, p. 182)
}

Quando esta discussão se torna mais específica para uma determinada área do conhecimento, aqui no caso o Ensino de Química, esta relação se torna ainda mais estreita. Vamos pensar quanto de química é utilizado e conhecido no universo doméstico? Uma dona de casa ao manusear material de limpeza vai ensinando o que aprendeu aos filhos a melhor forma de deixar a casa limpa. Contudo, o saber informal recebido e transmitido compreende os conhecimentos sobre os níveis de toxicidade dos materiais de limpeza doméstica? Como o ensino de química pode contribuir para a conscientização ambiental? Qual a contribuição do ensino de química diante de acidentes e primeiros socorros com produtos corrosivos de uso doméstico? E, antes de tudo, como o ensino de química pode chegar até essa população que não frequenta mais e bem provavelmente não voltará a frequentar os bancos escolares?

As competências pretendidas pelos documentos oficiais indicam que o papel do ensino de ciência torna-se tão amplo quanto à necessidade comum de uma sociedade. Pretende-se com este ensino, formar cidadãos capazes de tomar decisões importantes em benefício próprio e coletivo segundo as Orientações Curriculares Nacionais:

"O mundo atual exige que o estudante se posicione, julgue e tome decisões, e seja responsabilizado por isso. Essas são capacidades mentais construídas nas interações sociais vivenciadas na escola, em situações complexas que exigem novas formas de participação." (BRASIL, 2006). 
Neste processo de ensino-aprendizagem, participam diversos atores sociais, e suas contribuições podem, além de trazer diferentes pontos de vista, também apresentar escassez ou erro de conceito (SANTOS, 2006). Uma vez que a informação é dinâmica e os conhecimentos da Ciência são transitórios, o Ensino de Química adquire novas atribuições quando mais de um veículo de informação aborda o mesmo assunto. Além disso, é preciso estar atendo para a imagem transmitida da química como vilã quando se atribui a ela seu potencial poluente do ar, do solo e da água, esquecendo-se, ou dando pouca ênfase, de mostrar o outro lado da moeda que esta mesma química pode controlar as fontes poluidoras (Brasil, 2006).

A partir deste ponto observa-se a necessidade de um professor efetivamente engajado na formação de um cidadão crítico e atento aos seus direitos e deveres. Este profissional deve, então, analisar constantemente seu método em sala de aula, observando a região onde a escola está inserida para que possa verificar se o processo utilizado se aproxima da realidade local. O professor que tiver esse cuidado aumentará o grau de interesse dos seus alunos pelos conteúdos abordados.

\section{EDUCAÇÃO NÃO FORMAL E A EDUCAÇÃO QUÍMICA NO BRASIL}

A distância entre a escola, considerada como espaço formal de ensino, e o estudante tem estimulado a experiência de ensino-aprendizagem em espaços não formais de ensino destinados inicialmente à divulgação científica. Por formal e não formal, tendo ainda o informal, utilizamos como referência para o seu entendimento os trabalhos de Gohn (2014;2009; 2006). Segundo a autora, educação formal é dividida por séries onde o indivíduo deve cursá-las em uma ordem específica e ao fim deste processo, este adquire certificado. O local onde se educa é um ambiente com normas e regras, e o educador é sem dúvida o professor. Seus objetivos são previstos por legislação onde se espera a capacitação dos indivíduos para graus mais avançados (Gohn, 2006).

A educação informal é aquela em que o indivíduo adquire conhecimentos relativos ao grupo onde está inserido, diríamos os do senso comum, como expressão linguística, regras de etiqueta, contos populares, enfim, uma gama de saberes fundamentais para o convívio social. Não há um educador definido, cabendo a qualquer sujeito que detenha o conhecimento transmiti-lo aos demais, bem como não há um espaço físico delimitado, podendo este ocorrer em qualquer lugar a qualquer momento. Destaca-se ainda a intenção facultativa em educar, uma vez que o conhecimento pode 
ser adquirido apenas pela observação dos demais indivíduos. Logo, a característica principal deste espaço é a falta de planejamento de atividades e intencionalidades no processo de ensino-aprendizagem. Os exemplos mais claros são: o convívio com a família, o ambiente de trabalho, os momentos de lazer, a mídia etc.

A educação não formal é confundida muitas vezes com a educação informal, pois como na anterior não há séries nem certificados, não possui norma legislativa para seus objetivos e o papel do educador não fica centrado na figura do professor. Porém o que seria mais diferenciador entre esses dois é o aspecto da intencionalidade:

Na educação não-formal, os espaços educativos localizam-se em territórios que acompanham as trajetórias de vida dos grupos e indivíduos, fora das escolas, em locais informais, locais onde há processos interativos intencionais (a questão da intencionalidade é um elemento importante de diferenciação) (GOHN, 2006, p.32)

É possível perceber as várias possibilidades em relação aos espaços onde a educação não formal ocorre, desde espaços destinados à divulgação científica como Museus de Ciência, até espaços primeiramente denominados informais como clubes, centros sociais e casas de apoio quando nestes locais ocorrem intervenções educativas. Estas intervenções educativas podem ter diversos objetivos distintos bem como abordar tópicos diversos, como: educação ambiental, debates sobre igualdade racial, educação jurídica familiar etc. Todas com um planejamento antecipado a fim de alcançar objetivos específicos.

Salientando que o trabalho destes espaços não deve tomar o lugar da escola nem a escola deve exercer a função do primeiro, é interessante que haja uma interlocução que possibilite a troca de objetivos e ideais (MONTEIRO, 2009). Os assuntos instigados através dos momentos lúdicos de um espaço destinado à divulgação científica devem ser trabalhados de forma aprofundada em sala de aula, previsto nos documentos oficiais: "Qualquer que seja a atividade a ser desenvolvida, deve-se ter clara a necessidade de períodos pré e pós atividade, visando à construção dos conceitos.” (BRASIL, 2006).

Os alunos previamente preparados em suas aulas, aqui no caso as de química, juntamente com o professor qualificado podem apresentar um grande potencial de mudança na comunidade onde aquela escola está inserida, quando esta abre suas portas à população do seu entorno e os conscientiza acerca do conhecimento científico para o bem da comunidade. (ALBAGLI, 1996). 
Devido à inexistência de um currículo a ser seguido, os espaços não formais de ensino trazem a flexibilidade necessária para adaptação de temas relevantes à situação atual onde está localizado. Estes espaços oferecem a possibilidade de investigar como determinados assuntos são recebidos pela população, sem o peso da avaliação tradicional que a escola possui. As narrativas dos grupos que ali se encontram podem revelar as verdadeiras carências da região, o que por sua vez pode auxiliar na elaboração dos trabalhos para o processo de ensino-aprendizagem. O processo de ensinoaprendizagem é favorecido quando se constrói fortes relações dos diferentes espaços educacionais. Lucci respalda a nossa perspectiva trazendo os principais aspectos da psicologia sócio-histórica de Vigotsky destacando que: “o homem é um ser históricocultural; o homem é moldado pela cultura que ele próprio cria" e "o indivíduo é determinado nas interações sociais, ou seja, é por meio da relação com o outro e por ela própria que o indivíduo é determinado (...)" (LUCCI, 2006, p.5).

Ainda que bons frutos tenham sido colhidos da união entre escola e espaços não formais, os relatos restringem-se praticamente às experiências nos programas dos Centros e Museus de Ciência. Mesmo assim, percebe-se que a falta de acompanhamento do trabalho que está sendo desenvolvido impede que haja reestruturação objetiva para sanar as carências reais dos grupos, para que esses espaços possam atender bem, assim como suprir a falta de formação específica para os educadores.

\section{SEGURANÇA QUÍMICA NO COTIDIANO DOMICILIAR}

Segundo o Sistema Nacional de Informações Tóxico Farmacológicas (SINITOX) o número de casos de intoxicação humana por agentes tóxicos é crescente para os chamados domissanitários. Focando a Região Sudeste nos últimos nove anos registrados, observa-se que o maior caso de intoxicação é causado por medicamentos e em segundo por agentes domissanitários,

De acordo com a Agência Nacional de Vigilância Sanitária, ANVISA, estes dados não revelam o quadro total de intoxicação, uma vez que diversos casos não são relatados ao SINITOX, por não se tratar de intoxicação aguda e/ou crônica, por não ser diagnosticada corretamente e, ainda, pela existência de profissionais da saúde que desconhecem a importância da notificação. Analogamente, a população não dá importância às intoxicações leves como, por exemplo, pequenos desconfortos, desta forma os mesmos não procuram o serviço médico e associam este mal estar a cansaço e 
outros problemas de saúde. Existem, ainda, os efeitos tardios da exposição diária a domissanitários tais como efeitos mutagênicos e carcinogênicos.

Desde 1996 os domissinitários, no contexto nacional, lideram entre os três grupos mais frequentes de intoxicação humana, ocupando o segundo lugar nos casos com crianças de até cinco anos e o terceiro lugar nos casos de acidentes.

Dentre os problemas mais relatados temos a falta do uso de equipamento de proteção individual, ausência de informações nos rótulos quanto aos riscos ou apresentação dos mesmos de forma muito técnica, embalagens extremamente chamativas às crianças e produtos com aromatizantes que auxiliam a confundir estes produtos com alimentos.

Observa-se a partir destes dados a falta de conhecimento por parte da população sobre os possíveis efeitos de substâncias químicas sobre a saúde em função da diversidade dos ambientes cotidianos. A ausência do letramento científico pode ser um fator significante para o surgimento deste quadro que preocupa as autoridades da área da saúde (SANTOS, 2006).

Assumindo que este é um dos temas que deva estar contido na elaboração do planejamento dos cursos de Química presente na educação básica, pensou-se em um trabalho que pudesse investigar a real carência deste assunto com a população do entorno do IFRJ campus Nilópolis. O curso de Licenciatura em Química desta unidade possui como um de seus objetivos formar professores capazes de exercer a sua prática pedagógica de acordo com os interesses de apropriação do saber científico por toda sociedade.

A partir da prática de ensino experimentada em espaços não formais, o presente trabalho buscou avaliar como o tema "riscos químicos em ambientes domésticos" é recebido pela população, bem como avaliar através de questionários e narrativas o saber de senso comum sobre "químicos do cotidiano" de modo a contribuir para a relação dialética prática-teoria-prática (MARANDINO, 2003).

\section{ASPECTOS METODOLÓGICOS}

Durante um período de aproximadamente doze meses (2013-2014), realizamos visitas a quatro espaços não formais localizados próximos ao IFRJ campus Nilópolis, a citar:

1) Associação de Pais e Amigos dos Deficientes do Rio de Janeiro (APADERJ) com sede na Rua Maestro Djalma do Carmo no 121, Centro - Nilópolis. Uma 
instituição sem fins lucrativos com o objetivo de atender crianças e adolescentes com as mais diversas deficiências, objetivando desenvolver suas potencialidades para integrá-las à Sociedade e ao Mercado de Trabalho. Todos os que ali trabalham são voluntários das mais diversas áreas do conhecimento. Nosso trabalho neste espaço foi realizado com os pais das crianças que frequentam a Instituição totalizando um número de 32 participantes.

2) O Posto Médico Flávio do Couto Vieira, localizado na Rua José Filho, Parque Anchieta - Rio de Janeiro. Este centro médico municipal possui um programa de reeducação e intoxicação alimentar oferecido aos moradores da região, além de diversos outros programas. Nosso trabalho foi realizado com os pacientes deste programa com auxílio da nutricionista e contou com 9 participantes.

3) O Grupo da $3^{\text {a }}$ Idade de Olinda, com reuniões realizadas na Praça Matheus Vieira do Amaral, Rua Nilo Peçanha Olinda - Nilópolis. A visita realizada contou com 20 donas de casa.

4) O Posto de Saúde Nova Olinda, localizado na Rua Amadeu Lara S/N, OlindaNilópolis. Este posto médico possui um programa chamado Sala de Espera, onde os pacientes que aguardam atendimento recebem orientação sobre diversos assuntos e ocasionalmente palestras sobre sexualidade e drogas são oferecidas aos moradores. O número de participantes em nosso encontro foi de 25 pessoas.

Cabe salientar que todos os espaços visitados possuem programas de ensino não formal em suas estruturas e isto forneceu a credibilidade necessária para que a visita pudesse ser realizada.

Com o intuito de verificar nos grupos que participaram da pesquisa o quanto estes conheciam os riscos tóxicos que os domissanitários possuem, foram utilizados os dados disponíveis nos sites da ANVISA, da SINITOX e dos materiais de apoio disponibilizados pelo Dr. Afrânio Gomes Pinto Júnior (Disponível em: < http://ltc.nutes.ufrj.br/toxicologia/modVII.htm>. Acesso em: 07 de fevereiro de 2013). Destes dados, foram selecionados produtos químicos de uso doméstico com maior índice de intoxicação humana e acrescentamos algumas imagens disponíveis em outros domínios da Internet para montar uma apresentação em Microsoft Power Point@.

Esta apresentação objetivou criar entre os grupos, uma discussão acerca dos tópicos apresentados. Ao longo desta, procurou-se gerar um espaço para debate entre os participantes, evitando sempre que a visita fosse meramente informativa. Com este debate foi possível colher os relatos de experiência através de anotações, para que estes 
dados colaborassem com os colhidos através de um questionário. O questionário em questão foi aplicado antes de iniciar o diálogo com o grupo. O objetivo foi entender um pouco das concepções prévias do público ali presente, que não fazia ideia dos itens que seriam abordados. O questionário (Quadro 1) foi estruturado com perguntas fechadas e abertas. Alguns participantes tiveram dificuldades em responder as questões, uns por problemas de visão, outros por dificuldade de interpretação. Para estes, os questionários foram aplicados verbalmente antes de se iniciar o debate.

Quadro1 - Questionário aplicado

\begin{tabular}{|c|c|}
\hline \multicolumn{2}{|c|}{ Questionário } \\
\hline 1 - Idade & $\begin{array}{l}9 \text { - Quando um produto de limpeza acaba o } \\
\text { que você faz com a embalagem? } \\
\text { a) Reutiliza com outros produtos; } \\
\text { b) Reutiliza com o mesmo tipo de } \\
\text { produto; } \\
\text { c) Joga no lixo; } \\
\text { d) Reutiliza para outros fins como } \\
\text { artesanato, trabalhos escolares e etc. }\end{array}$ \\
\hline $2-$ Sexo & $\begin{array}{l}10 \text { - Para limpar verduras devemos primeiro } \\
\text { deixá-las em uma mistura de água e água } \\
\text { sanitária. Como esta limpeza deve ser } \\
\text { realizada? Onde você aprendeu? }\end{array}$ \\
\hline 3 - Profissão & $\begin{array}{l}11 \text { - Em caso de intoxicação por ingestão de } \\
\text { produtos de limpeza, como água sanitária, ou } \\
\text { por inalação de aguarrás, o que se deve fazer? }\end{array}$ \\
\hline $\begin{array}{l}\text { 4- Escolaridade } \\
\text { a) Ensino fundamental incompleto } \\
\text { b) Ensino fundamental completo } \\
\text { c) Ensino médio incompleto } \\
\text { d) Ensino médio completo } \\
\text { e) Ensino superior incompleto } \\
\text { f) Ensino superior completo }\end{array}$ & $\begin{array}{l}\text { 12 - Se durante uma faxina algum produto de } \\
\text { limpeza espirrar nos olhos, causando irritação } \\
\text { e ardência, o que se deve fazer? } \\
\text { a) Lavar os olhos em água corrente e ir } \\
\text { imediatamente para a emergência de } \\
\text { um hospital; } \\
\text { b) Lavar com soro fisiológico e ir } \\
\text { imediatamente para a emergência de } \\
\text { um hospital; } \\
\text { c) Não passar nada nos olhos e ir } \\
\text { imediatamente para a emergência } \\
\text { hospital; } \\
\text { d) Lavar os olhos em água corrente e } \\
\text { observar para levar ao médico } \\
\text { especializado; } \\
\text { e) Lavar com soro fisiológico e observar } \\
\text { para levar ao médico especializado; } \\
\text { f) Não passar nada nos olhos e observar } \\
\text { para levar ao médico especializado; }\end{array}$ \\
\hline $\begin{array}{l}5 \text { - Você costuma ler os rótulos dos produtos } \\
\text { de limpeza que tem em casa? }\end{array}$ & $\begin{array}{l}13 \text { - Em caso de acidente como furos no } \\
\text { botijão de gás, deve-se levar o botijão para } \\
\text { fora de casa e chamar os bombeiros. Qual dos } \\
\text { números de emergências abaixo pertence aos } \\
\text { bombeiros? } \\
\begin{array}{lllll}\text { a) } 102 b) 190 & \text { c) } 191 & \text { d) } 192 & \text { e) } 193 & \text { f) } 194 \\
\text { g) } 199 & & & \end{array}\end{array}$ \\
\hline
\end{tabular}




\begin{tabular}{|c|c|}
\hline $\begin{array}{l}6-\text { Em que local você costuma guardar seus } \\
\text { produtos de limpeza? }\end{array}$ & $\begin{array}{l}14 \text { - A válvula e a mangueira do botijão de gás } \\
\text { possuem prazo de validade? Se sim, qual o } \\
\text { período de troca? }\end{array}$ \\
\hline $\begin{array}{l}7 \text { - Qual é o material de limpeza que você } \\
\text { mais usa? }\end{array}$ & $\begin{array}{l}15 \text { - Ao comprar seus produtos de limpeza, } \\
\text { você costuma seguir: } \\
\text { a) preços mais em conta; } \\
\text { b) propagandas exibidas na televisão. } \\
\text { c) o que os rótulos dos produtos indicam; } \\
\text { d) as marcas mais antigas; } \\
\text { e) indicações de pessoas amigas; } \\
\text { Outras: }\end{array}$ \\
\hline
\end{tabular}

Após a aplicação do questionário, iniciamos com uma breve explicação sobre os objetivos daquele encontro e porque iríamos falar sobre produtos de limpeza, apresentando os dados de intoxicação humana por domissanitários e óbitos gerados pelos mesmos.

Buscando remover a ideia do público de que a visita tratava-se de uma aula, incitamos uma pequena brincadeira, intitulada "Você seria capaz de diferenciar?" visando animar o ambiente. Para isso foram apresentadas diversas imagens de produtos de limpeza ao lado de alguns alimentos e pedimos para que indicassem qual era o domissanitário e qual era o alimento. Para esta atividade pegamos imagens no site do professor Dr. Afrânio Gomes (http://ltc.nutes.ufrj.br/toxicologia/modVII.htm).

Através de uma ótica CTS (CIÊNCIA-TECNOLOGIA-SOCIEDADE), buscamos incitar a discussão para um assunto ligado a Química do cotidiano. Escolhemos esta metodologia de caráter investigativo por crermos que enfatiza a descrição, a indução, a teoria fundamental e o estudo das percepções pessoais (BORDAN \& BIKLEN, 1994).

Em sequência, o seguinte tópico foi abordado: a importância das informações contidas nos rótulos e onde armazenar os domissanitários. Esse foco de discussão foi norteado pelo elevado número de acidentes envolvendo crianças, quase sempre ocasionados pela leitura displicente e indevida de rótulos. Nesse momento imagens foram apresentadas para que os debates junto ao público se iniciassem.

A partir deste ponto, os domissanitários mais citados nos casos de intoxicação humana foram debatidos com o público. Os debates foram iniciados com questionamentos realizados acerca do uso apropriado dos produtos e alguns diálogos sobre os termos populares e comerciais dos domissanitários. A ordem dos produtos apresentados foi: 1) Água Sanitária $\left(\mathrm{NaCIO}_{(\mathrm{aq})}\right)$; 2) Antissépticos Populares; 3) Alvejante; 4) Sabão Detergente. 
Uma atenção maior foi dada a água sanitária devido ao seu alto grau de toxicidade e também por possuir maior índice de acidente envolvendo crianças menores de cinco anos. Foi também alertado o conceito do cloro ativo, que vem sendo relatado na mídia constantemente com pouca explicação do seu significado. Trabalhamos lançando as seguintes indagações: "Cloro, hiploclorito e água sanitária são a mesma coisa?" E "o que é cloro ativo?"

O debate com antissépticos populares objetivou demonstrar sua toxicidade tendo em vista a facilidade de compra destes produtos e os perigos da automedicação. Também foram abordados os alvejantes, sabões e detergentes.

Os riscos à saúde foram apresentados reforçados através da apresentação de fotos contendo imagens de partes do corpo com marcas decorrentes de exposição direta da pele ao produto, sendo recorrente atingir as mãos; os olhos pelos gases tóxicos liberados pelas substâncias e na língua quando acidentalmente a pessoa ingere, sendo mais comum a ingestão de água sanitária. Estes acidentes com o uso de domissanitários decorrem do uso prolongado de determinados produtos sem o manuseio correto.

Com o uso destas fortes imagens o tópico equipamento de proteção individual (EPI) foi abordado. Este debate pretendeu salientar a diferença do uso destes equipamentos em ambientes domésticos e em outros setores. O público foi instigado a apresentar possíveis soluções para o uso de alguns equipamentos quando o mesmo não é viável no uso doméstico.

Em sequência, o tema misturas caseiras foi trabalhado com o uso de uma reportagem exibida por uma grande rede de TV. Neste vídeo situações reais de intoxicação causada por uso contínuo de produtos de limpeza e por misturas indevidas são apresentados de forma simples e acessível a quem não conhece determinados conceitos químicos.

Para debater acerca dos primeiros socorros em caso de intoxicação por domissanitários, foram apresentadas noções de primeiros socorros. Cabe salientar que apesar das informações transmitidas pressuporem que o público deva conhecer a diferença de ácido e base, foi esclarecido durante os debates que caso a natureza do domissanitário fosse desconhecida, o uso de água em todos os casos era o mais indicado pelos especialistas.

Durante todo o processo permitimos que houvesse troca de experiência e debate sobre a melhor forma de solucionar os problemas apresentados, evitando 
Ensino, Saúde e Ambiente - V9 (3), pp. 283-296, Dez. 2016

oferecer respostas prontas que não consideram a realidade dos participantes. Escolhemos utilizar esta metodologia de caráter investigativo por crermos que enfatiza a descrição, a indução, a teoria fundamental e o estudo das percepções pessoais (BOGDAN \& BIKLEN, 1994)

\section{RESULTADOS OBTIDOS}

A princípio, o público apresentou resistência ao diálogo por medo de errar as "respostas", e desta forma a dinâmica inicial foi fundamental para minimizar a tensão e criar um ambiente descontraído.

As respostas obtidas nos questionários da primeira visita expressaram resultados significativos em relação ao conhecimento prévio do público, onde percebemos que o assunto agrotóxico é muito difundido na mídia, uma vez que $45 \%$ do público responderam que sua utilização é para "matar pragas". Porém o assunto ainda carece de maior explicação, pois $35 \%$ confundiram pesticidas com fertilizantes. O quadro é mais preocupante com o resultado, quando questionados sobre o armazenamento de produtos de limpeza: $88 \%$ não soube responder corretamente.

A análise feita do primeiro grupo foi fundamental para compreender e ampliar as respostas obtidas pelos questionários na segunda visita, nos levando a reformular a abordagem com os grupos, permitindo maior interação entre os mesmos.

Sobre o armazenamento dos produtos de limpeza, $75 \%$ do segundo grupo responderam que os guardava em baixo da pia ou do tanque. Vale ressaltar que durante a palestra percebemos que $80 \%$ do grupo tinham crianças pequenas em casa.

Foi também durante a apresentação que duas senhoras do grupo relataram casos de acidentes com produtos de limpeza, a primeira narrando que o filho foi intoxicado com a ingestão de água sanitária, tendo sido internado em estado grave. A segunda senhora contou que sua irmã guardava água sanitária na geladeira por crer que conservaria este produto por mais tempo.

A partir daí o grupo foi questionado sobre os primeiros socorros em casos de intoxicação, e o leite foi considerado antídoto por $80 \%$ do público, revelando ser esta uma questão ainda preocupante, pois assuntos de segurança química são desconhecidos, mesmo em um grupo que apresentou 70\% dos participantes com o Ensino Médio e 10\% o Ensino Superior. Este dado demonstra como o conhecimento obtido em ambiente informal pode ser definidor da forma como as pessoas se situam no mundo social.

Os casos de doenças adquiridas por uso contínuo de produtos de limpeza foram 
encontrados nos discursos durante a apresentação: "Eu descobri que tinha perdido minhas digitais quando precisei tirar um documento... trabalhei por muito tempo com produtos de limpeza sem luva" (Participante 1). Alguns casos de dermatite foram relatados, após exibição de algumas fotos sobre o problema: “... minha mão fica assim depois que lavo a louça, mas não consigo trabalhar de luva.” (Participante 2). Foi possível perceber que as pessoas conheciam Equipamentos de Proteção Individual (EPI) bem como sua utilização em cada tarefa, no entanto desconheciam a importância do uso destes, ao menos no próprio cotidiano.

Os domissanitários por serem utilizados no dia-a-dia trazem a falsa impressão de baixo risco e toxicidade, todos participantes revelaram não saber dos problemas ocasionados por misturas de produtos de limpeza: "costumo fazer experiências para limpar as coisas, tem um blog na internet que ensina algumas misturas" (Participante 3). Dessas misturas destacou-se água sanitária + sabão em pó (25\%), água sanitária + desinfetante (50\%) e desengordurante + água sanitária (10\%).

\section{CONSIDERAÇÕES FINAIS}

A reflexão feita através do discurso do público participante oferece a possibilidade de criação de materiais direcionados às lacunas encontradas, isto gera, por sua vez, a aproximação necessária entre escola e comunidade para que o processo ensino-aprendizagem seja significativo às pessoas ali presentes. $\mathrm{O}$ interesse dos grupos, que a princípio expuseram relutância ao tema, foi despertado quando estes se tornaram interlocutores da apresentação, sugerindo soluções e relatando experiências. Esta proximidade foi fundamental ao alcance dos objetivos da pesquisa. Ao longo das exposições o trabalho modificou-se a fim de sanar as carências sobre o tema riscos químicos, agregando sugestões do público e as dificuldades percebidas. Estas modificações deram suporte para elaboração de um material interativo contento o maior número possível de informações de como reconhecer e evitar acidentes e ter noções de primeiros socorros. Para isto a inserção da temática em espaços extramuros da escola, foi fundamental para entender os reais saberes da população a fim de realizar um trabalho direcionado e significativo, uma prática que se associa à democratização dos conhecimentos gerados nos cursos de graduação. Os dados revelam ainda, o baixo conhecimento dos grupos sobre os riscos químicos presente em seus lares, as medidas de segurança e os primeiros socorros diante de intoxicações. Alcançar o letramento científico e tecnológico capaz de sanar esta carência reconhecida durante a pesquisa é 
um desafio que precisa ser discutido na formação do licenciado em química e na formação continuada, a fim de que os objetivos educacionais permitam que os alunos sejam capazes de exercer sua cidadania.

A prática da educação em espaços não formal realizada por licenciando, aqui no caso o de Química, permite o exercício da liberdade tanto da escolha dos assuntos quanto da forma como abordá-los. Essa possibilidade permite, ainda, uma maior chance de aproximação com os interesses da população. Ao perceber este interesse e ao praticar novos formatos, o licenciando estará se alimentando de inovações que poderão ser utilizadas em sala de aula. Neste sentido, consideramos extremamente importante o incentivo nas Licenciaturas do uso dos espaços não formais como novos campos da prática de ensino.

\section{REFERÊNCIAS}

ALBAGLI, S. Divulgação Científica: Informação Científica para a Cidadania? Ci. Inf. Brasília, vol. 25, n.3, p 396-404, 1996.

BRASIL. Orientações Curriculares Nacionais para o Ensino Médio: Ciências Naturais, Matemática e suas Tecnologias. Brasília: Ministério da Educação, Secretaria de Educação Básica, vol.2, 2006.

Parâmetros Curriculares Nacionais (Ensino Médio). Brasília: Ministério da Educação, Secretaria de Educação Básica, 2006(a).

CAZELLI, S. Ciência, Cultura, Museus, Jovens e Escolas: Quais as Relações? Tese de Doutorado apresentada no Programa de Pós-Graduação em Educação do Departamento de Educação do Centro de Teologia e Ciências Humanas da PUC-Rio, 2005.

GASPAR, A. A Educação Formal e a Educação Informal em Ciências. In: LuisaMassarani, Ildeu de Castro Moreira e Fatima Brito. (Org.). Ciência e público: caminhos da divulgação científica no Brasil. $1^{\mathrm{a}} \mathrm{ed}$. Rio de Janeiro: Casa da Ciência Centro Cultural de Ciência e Tecnologia/UFRJ, 2002.

GOHN, M. G. Educação não-formal, participações da sociedade civil e estruturas colegiadas nas escolas. Rio de Janeiro: Ensaio: aval.pol.públ.Educ., vol. 14, n.50, p 27-38, 2006.

Educação não-formal e o papel do educador(a) social e os projetos sociais de inclusão social. Ensaio (Fundação Cesgranrio. Impresso), v. 1, p. 24-37, 2009.

Editora, 2014.

Sociologia dos Movimentos Sociais. $2^{\mathrm{a}}$ ed., São Paulo: Cortez

LUCCI, M. A. A Proposta de Vygotsky: A Psicologia Sócio-Histórica. Espanha: Profesorado. Revista de Currículum y Formación Del Profesorado, vol. 10, n.2, 2006. Disponível em http://www.ugr.es/ recfpro/rev102COL2port.pdf; 
Ensino, Saúde e Ambiente - V9 (3), pp. 283-296, Dez. 2016

MARANDINO, M. A Prática de Ensino nas Licenciaturas e a Pesquisa em Ensino de Ciências: Questões Atuais. Caderno Brasileiro de Ensino de Física, Florianópolis, v. 20, n.2, p. 168-193, 2003.

MONTEIRO, B. A. P; MARTINS, I; GOUVÊA, G.Espaços Não Formais de Educação e os Discursos Presentes na Formação Inicial de Professores de Química. In: VII ENPEC - Encontro Nacional de Pesquisa em Educação em Ciência, 2009, Florianópolis. Anais VII ENPEC, 2009.

SANTOS, W.L.P.. Letramento em Química, Educação Planetária e Inclusão Social. Quím. Nova, vol.29, nº.3, São Paulo, 2006. 